\title{
PREDIKSI KONSENTRASI INOKULUM DAN UMUR FERMENTASI PADA TEMPE MENGGUNAKAN LARIK SENSOR GAS DENGAN METODE JARINGAN SYARAF TIRUAN
}

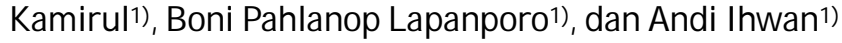 \\ 1)Program Studi Fisika Fakultas Matematika dan Ilmu Pengetahuan Alam \\ Universitas Tanjungpura \\ Pontianak, Indonesia \\ Email : mirulvka@gmail.com
}

\begin{abstract}
Abstrak
Telah dilakukan penelitian tentang prediksi konsentrasi inokulum dan umur fermentasi pada tempe menggunakan sistem larik sensor gas. Sistem larik sensor gas terdiri dari 3 subsistem yaitu pengindera, elektronik, dan pengolahan data. Subsistem pengindera dirancang menggunakan sensor MQ-3, MQ-4, dan MG-811 yang masing-masing peka terhadap perubahan kadar gas alkohol, metana, dan karbondioksida. Sebagai subsistem elektronik digunakan mikrokontroler ATMega328P yang berfungsi sebagai elemen pemroses data keluaran dari sensor gas. Sedangkan sebagai subsistem pengolahan data digunakan Jaringan Syaraf Tiruan (JST) propagasi balik sebagai salah satu metode prediksi yang akurat. Hasil simulasi menunjukkan bahwa model mampu mengikuti pola keluaran konsentrasi inokulum dan umur fermentasi tempe dengan korelasi yang sama yaitu 0,99, dengan MSE (Mean Squared Error) sebesar $1,78.10^{-4}$ dan $8,83.10^{-4}$. Nilai korelasi konsentrasi inokulum dan umur fermentasi menggunakan data pengujian masing-masing sebesar 0,98 dan 0,99 dengan MSE 8,92.10-5 dan 2,31.10-3 .
\end{abstract}

Kata kunci : inokulum, fermentasi, sensor gas, JST

\section{Pendahuluan}

Sebagai bahan makanan tradisional dan menjadi ciri khas bagi masyarakat Indonesia, tempe harus memiliki standar mutu dan kualitas tertentu agar memberikan manfaat kesehatan yang besar. Berdasarkan penelitian yang dilakukan oleh Kumalasari (2012) kualitas fisik dan kimia yang optimal didapatkan dengan konsentrasi inokulum 0,15 \% w/w (setiap 100 gram kedelai dicampur dengan 0,15 gram inokulum). Selain itu, kualitas tempe juga sangat ditentukan oleh umur fermentasi.

Salah satu cara untuk mengetahui umur fermentasi tempe adalah dengan memanfaatkan salah satu sifat fisik tempe yaitu aroma. Aroma yang dihasilkan selama fermentasi dapat dideteksi dengan sistem larik sensor gas. Prinsip kerja dari sistem larik sensor gas mirip dengan sistem penciuman manusia dimana uji kualitas tempe dilakukan berdasarkan aroma yang dihasilkan selama proses fermentasi tempe.

Penelitian ini bertujuan untuk merancang dan membuat sistem pengindera yang terdiri dari 3 buah sensor gas. Selanjutnya data keluaran sensor gas tersebut dijadikan data masukan untuk membangun JST yang mampu memprediksi konsentrasi inokulum dan umur fermentasi pada tempe. Hasil dari penelitian ini diharapkan dapat dijadikan alat pengontrol kualitas tempe. Hal ini dirasakan perlu karena tempe dengan konsentrasi inokulum yang tidak seimbang dan umur fermentasi yang terlalu lama tidak aman untuk dikonsumsi.

\section{Landasan Teori}

\subsection{Inokulum dan Fermentasi Tempe}

Tempe merupakan produk hasil fermentasi kedelai yang sudah lama dikenal di Indonesia. Faktor terpenting dalam pembuatan tempe adalah inokulum atau laru yang mengandung kapang. Inokulum pada tempe berfungsi sebagai agensia pengubah kedelai yang telah mengalami proses perendaman dan perebusan menjadi tempe. Jenis kapang yang berperan dalam fermentasi tempe adalah Rhizopus oligosporus, Rhizopus stolonifer, dan Rhizopus arrhizus (Kasmidjo, 1990).

Aroma spesifik pada tempe terbentuk akibat adanya senyawa-senyawa volatil dan nonvolatil yang terkandung di dalamnya. Senyawasenyawa volatil tersebut antara lain adalah metana, etana, n-heksana, 2-propanon, 2heptanol, dan 2,4 dekadiena. Sedangkan senyawa non-volatil terdiri dari ester karbonil dan asam karbonilat (Dewi, 2010).

\subsection{Sensor Gas Semikonduktor}

Sensor secara umum didefinisikan sebagai alat yang mampu menangkap fenomena kimia atau fisika, kemudian mengubahnya menjadi sinyal listrik baik arus listrik ataupun tegangan. Sedangkan sensor gas semikondutor adalah sejumlah komponen elektronik yang menggunakan sifat-sifat material semikonduktor, diantaranya Timah oksida, Silikon, Germanium, dan Gallium arsenide. Pada dasarnya elemen sensor yang digunakan dalam 
pembuatan sensor gas semikonduktor adalah material Timah oksida. Hal ini dikarenakan material Timah oksida memiliki sensitifitas yang tinggi, bobot yang ringan, serta sudah tersedia luas dipasaran (Oktorizal, 2010).

\subsection{Jaringan Syaraf Tiruan (JST)}

Jaringan Syaraf Tiruan (JST) merupakan kecerdasan buatan yang memiliki karakteristik mirip dengan jaringan syaraf biologis. JST dibangun dengan prinsip dasar perambatan sinyal-sinyal impuls yang dilatih terus-menerus dengan algoritma tertentu sehingga dapat mengenal pola masukan yang diberikan (Kusumadewi, 2004).

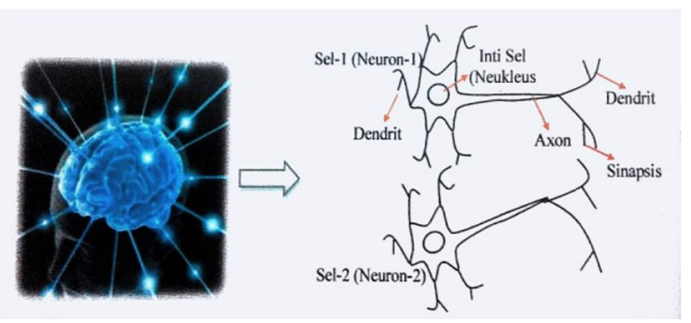

Gambar 1. Susunan syaraf pada otak manusia (Kusumadewi, 2004)

Gambar 1 menunjukkan komponenkomponen yang terdapat pada jaringan syaraf biologis. Setiap sel syaraf memiliki satu inti sel (nucleus) yang berperan sebagai pusat pemroses. Setiap informasi yang masuk diterima oleh rambut-rambut sel (dendrit), kemudian dijumlahkan di dalam nucleus dan dikirim melalui batang sel (axon) ke dendrit akhir yang bersentuhan dengan dendrit dari neuron yang lain (Kusumadewi, 2004).

Proses pengenalan pola oleh Jaringan Syaraf Tiruan diilustrasikan pada Gambar 2. Sinyal masukan yang dinotasikan dengan $\mathrm{x}_{1}$, $\mathrm{x}_{2}, \ldots, \mathrm{x}_{\mathrm{n}}$ dikalikan dengan sejumlah bobot $\mathrm{w}$ dan dijumlahkan dengan bobot bias b. Hasil perkalian dan penjumlahan a akan diaktifkan menggunakan fungsi aktivasi $\mathrm{F}$ tertentu untuk mendapatkan keluaran jaringan Y. Pemilihan fungsi aktivasi disesuaikan dengan tujuan dan tipe data keluaran yang diinginkan (Dhaneswara, 2004).

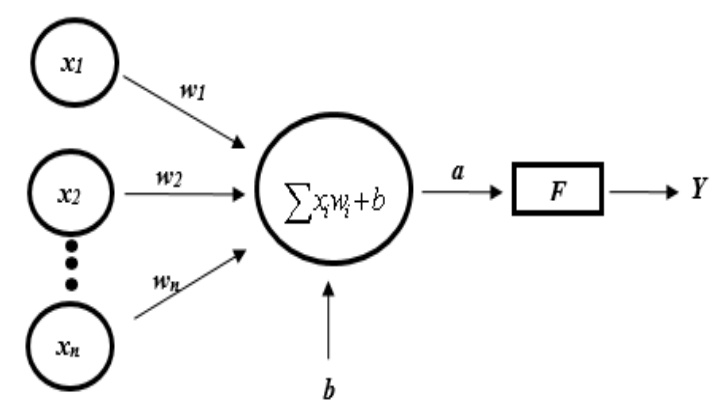

Gambar 2. Model JST sebagai tiruan dari neuron biologis (Dhaneswara, 2004)

\section{Metodologi}

Secara umum cara kerja sistem larik sensor gas adalah mengukur tegangan sampel gas kemudian data tersebut disimpan ke dalam SD Card tiap selang waktu 10 menit. Tahap perancangan larik sensor gas menggunakan beberapa komponen elektronik diantaranya sensor gas MQ-3, MQ-4, MG-811, mikrokontroler ATMega328P, dan RTC (Real Time Clock). Diagram blok sistem larik sensor gas secara keseluruhan ditunjukkan pada Gambar 3.

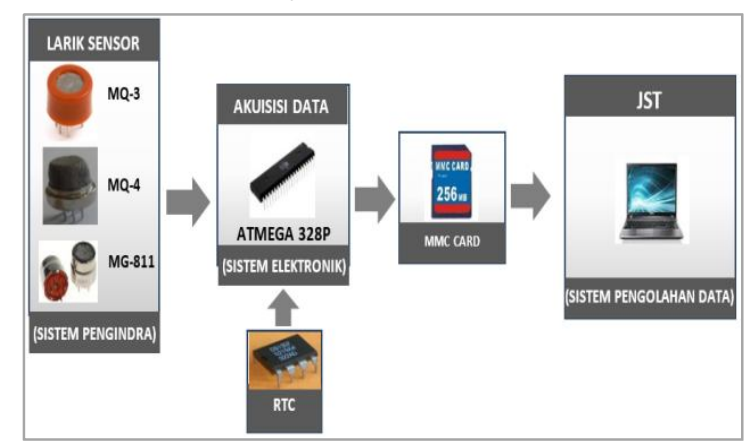

Gambar 3. Diagram blok sistem sensor gas

Perancangan JST dilakukan untuk memilih arsitektur JST yang sesuai serta menentukan jumlah lapisan, bobot awal tiap lapisan, serta parameter pelatihan. Sampel yang digunakan dalam penilitian ini adalah kedelai yang difermentasi dengan kadar inokulum masingmasing $0,1 \% \mathrm{w} / \mathrm{w}, 0,15 \mathrm{w} / \mathrm{w}, 0,20 \% \mathrm{w} / \mathrm{w}, 0,25$ $\% \mathrm{w} / \mathrm{w}$, dan 0,30\% w/w. Tahapan akuisisi data dilakukan untuk mengukur tegangan keluaran masing-masing sampel tempe selama proses fermentasi. Pada penelitian ini akuisisi data dilakukan selama 3 hari untuk tiap sampel dengan selang pengambilan data adalah 10 menit. Pengolahan data dilakukan untuk mengenali dan mempelajari pola keluaran larik sensor gas dengan metode JST. Selanjutnya, jaringan yang sudah terlatih dapat digunakan untuk memprediksi kadar inokulum dan umur fermentasi sampel tempe.

\section{Hasil dan Diskusi}

Larik sensor gas dirancang terpisah menjadi 2 bagian yaitu bagian pengindera dan bagian pengontrol. Bagian pengindera dan bagian pengontrol ditunjukkan pada Gambar 4

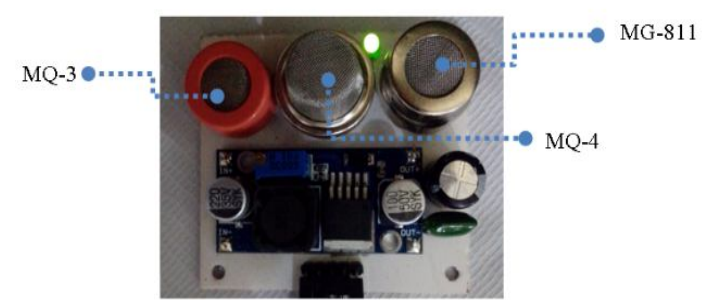

dan Gambar 5.

Gambar 4. Bagian pengindera sensor gas 
Bagian pengindera terdiri dari 3 buah sensor gas yaitu MQ-3, MQ-4, dan MG-811 yang berfungsi untuk mengukur tegangan sampel gas alkohol, metana, dan karbondioksida. Sedangkan bagian kedua merupakan bagian pengontrol yang berfungsi untuk mengoperasikan larik sensor gas. Bagian pengontrol terdiri dari komponen RTC, IC regulator, modul SD Card, dan tombol reset.

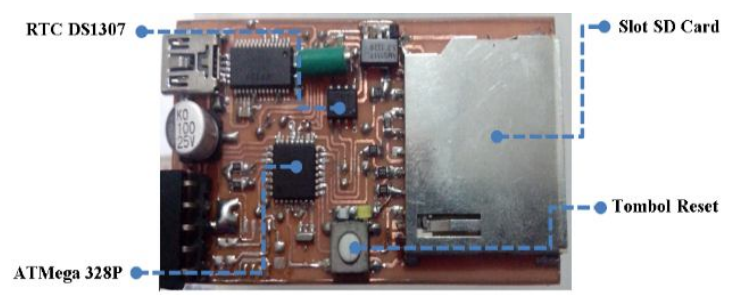

Gambar 5. Bagian pengontrol larik sensor gas

\subsection{Uji Kestabilan Sensor}

Uji kestabilan sensor dilakukan agar dapat mengetahui kapan waktu yang tepat untuk melakukan akuisisi data. Teknis uji kestabilan sensor adalah dengan mengukur tegangan pada ruang sensor dalam keadaan tertutup rapat sehingga tegangan yang terukur oleh larik sensor gas merupakan tegangan udara tanpa adanya sampel. Proses uji stabilitas sensor diperlihatkan pada Gambar 6.

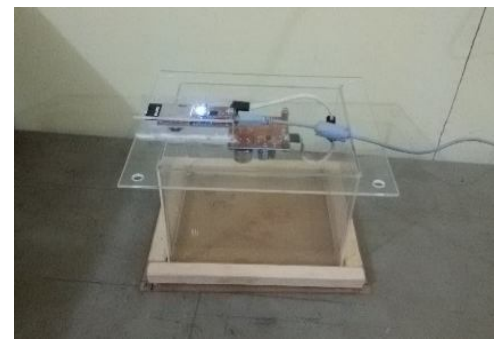

Gambar 6. Proses uji stabilitas larik sensor gas

Hasil uji stabilitas sensor ditunjukkan pada Gambar 7. Sensor dikatakan stabil apabila nilai tegangan yang terukur tidak berubah-ubah, karena pada ruang tertutup tidak ada sirkulasi udara (gas) sehingga tidak memungkinkan terjadinya perubahan konsentrasi gas. Grafik hasil uji kestabilan sensor menunjukkan bahwa sensor mulai stabil setelah dinyalakan selama 32 menit.

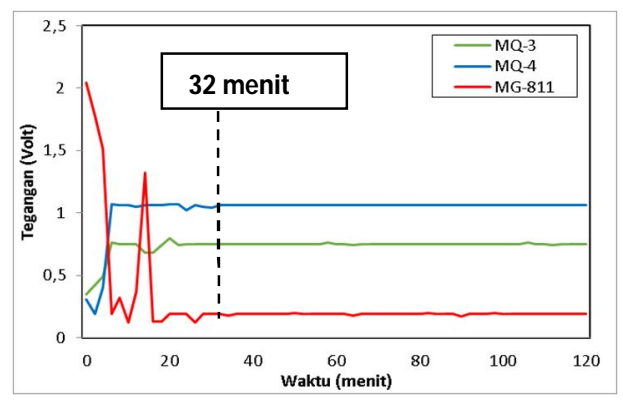

Gambar 7. Grafik hasil pengujian kestabilan sensor
Proses akuisisi data ditunjukkan pada Gambar 8. Akuisisi data merupakan proses pngukuran tegangan gas yang dihasilkan oleh sampel tempe yang dilakukan selama 3 hari dengan selang pengambilan data adalah 10 menit. Kemudian data tersebut disimpan ke SD Card untuk selanjutnya digunakan sebagai data masukan untuk membangun Jaringan Syaraf Tiruan.

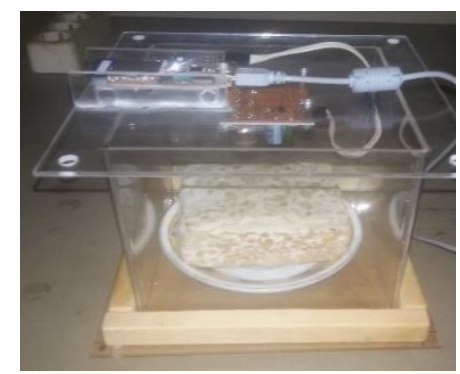

Gambar 8. Proses akuisisi data sampel

\subsection{Pengenalan Pola Keluaran Sensor dengan Metode JST}

Pengenalan pola keluaran larik sensor gas terdiri dari dua tahap. Tahap pertama adalah pelatihan, sedangkan tahap kedua adalah prediksi. Pelatihan merupakan proses mengenal pola dari data masukan yang diberikan, yaitu set data pelatihan. Data pelatihan menggunakan $70 \%$ dari total 2160 set data. Sisanya, 30\% digunakan sebagai data pengujian. Pelatihan JST dilakukan untuk menyesuaikan nilai bobot yang ditetapkan di awal pelatihan supaya dihasilkan jaringan terlatih dengan bobot akhir yang optimal. Dalam penelitian ini arsitektur JST yang digunakan adalah [50 252010 2].

Simulasi model menggunakan data pelatihan menghasilkan korelasi yang sama untuk konsentrasi inokulum dan umur fermentasi tempe yaitu sebesar 0,99. Simulasi hasil pelatihan di tampilkan pada Gambar 9 dan Gambar 10.

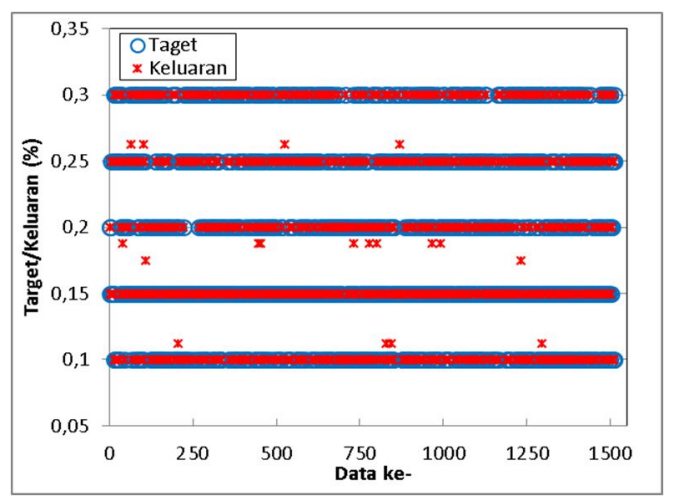

Gambar 9. Hasil simulasi antara T dan Y untuk konsentrasi inokulum pada data pelatihan 


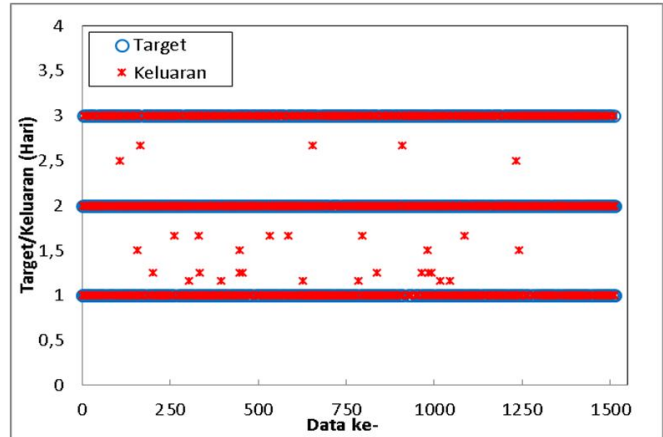

Gambar 10. Hasil simulasi antara T dan Y untuk umur fermentasi pada data pelatihan

Simulasi antara data target (T) dan keluaran jaringan (Y) ditampilkan untuk melihat seberapa dekat nilai kedua data tersebut. Dari hasil simulasi, nilai MSE masingmasing untuk konsentrasi inokulum dan umur fermentasi adalah sebesar 1,78.10-4 dan 8,83.10-4. Hal ini menunjukkan jaringan hasil pelatihan mampu mengikuti pola data target yang diberikan di awal pelatihan dengan sangat baik. Sedangkan hasil simulasi menggunakan data uji ditampilkan pada Gambar 11 dan Gambar 12.

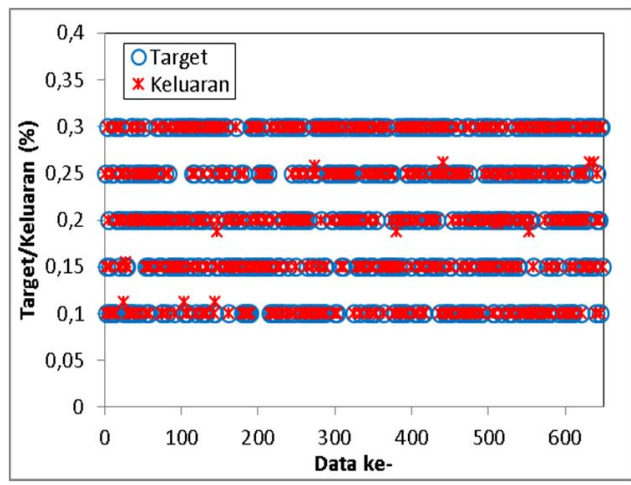

Gambar 11. Hasil simulasi antara T dan Y untuk konsentrasi inokulum pada data uji

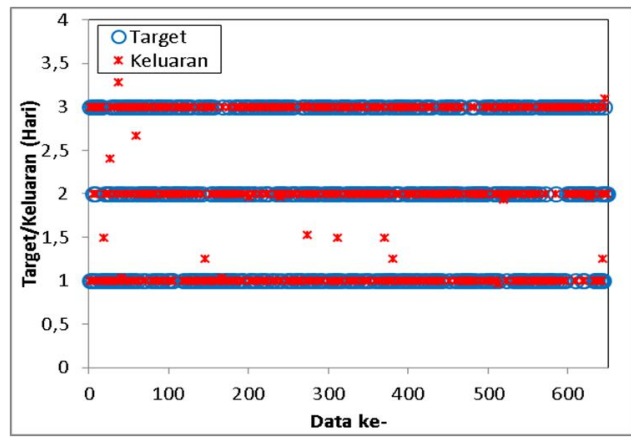

Gambar 12. Hasil simulasi antara T dan Y untuk umur fermentasi pada data uji

Simulasi antara T dan Y menunjukkan nilai MSE masing-masing untuk konsentrasi inokulum dan umur fermentasi tempe adalah sebesar 8,92.10-5 dan 2,31.10-3. Secara keseluruhan jaringan hasil pelatihan mampu menghasilkan nilai korelasi yang mendekati 1 dengan MSE yang kecil, oleh karena itu jaringan hasil pelatihan dapat digunakan untuk proses prediksi.

\subsection{Prediksi Konsentrasi Inokulum dan Umur Fermentasi Tempe}

Tahapan prediksi adalah tahapan dimana jaringan terlatih yang sudah teruji digunakan untuk memprediksi secara langsung data lapangan. Hasil prediksi menggunakan JST terlatih ditampilkan pada tabel 1.

Tabel 1. Hasil prediksi menggunakan JST terlatih.

\begin{tabular}{|c|c|c|c|c|c|}
\hline Sampel & $\begin{array}{l}\text { MQ-3 } \\
\text { (volt) }\end{array}$ & $\begin{array}{l}\text { MQ-4 } \\
\text { (volt) }\end{array}$ & $\begin{array}{c}\text { MG-811 } \\
\text { (volt) }\end{array}$ & $\begin{array}{c}\text { Konsentrasi } \\
\text { Inokulum } \\
(\%)\end{array}$ & $\begin{array}{c}\text { Umur } \\
\text { Fermentasi } \\
\text { (Hari) }\end{array}$ \\
\hline \multirow{5}{*}{1} & 3,13 & 3,96 & 0,47 & 0,15 & 2 \\
\hline & 2,99 & 3,95 & 0,47 & 0,15 & 2 \\
\hline & 2,98 & 3,94 & 0,47 & 0,15 & 2 \\
\hline & 2,96 & 3,93 & 0,47 & 0,15 & 2 \\
\hline & 2,95 & 3,92 & 0,47 & 0,15 & 2 \\
\hline \multirow{5}{*}{2} & 2,92 & 3,9 & 0,47 & 0,15 & 2 \\
\hline & 2,88 & 3,89 & 0,42 & 0,16 & 2 \\
\hline & 2,86 & 3,88 & 0,47 & 0,17 & 2 \\
\hline & 2,82 & 3,87 & 0,42 & 0,24 & 2 \\
\hline & 2,84 & 3,87 & 0,47 & 0,18 & 2 \\
\hline \multirow{5}{*}{3} & 2,73 & 3,86 & 0,45 & 0,29 & 1 \\
\hline & 2,72 & 3,86 & 0,47 & 0,24 & 2 \\
\hline & 2,8 & 3,85 & 0,45 & 0,15 & 2 \\
\hline & 2,78 & 3,84 & 0,45 & 0,15 & 2 \\
\hline & 2,77 & 3,83 & 0,45 & 0,15 & 2 \\
\hline \multirow{5}{*}{4} & 2,75 & 3,82 & 0,42 & 0,22 & 2 \\
\hline & 2,74 & 3,81 & 0,42 & 0,21 & 2 \\
\hline & 2,73 & 3,80 & 0,42 & 0,19 & 2 \\
\hline & 2,72 & 3,80 & 0,42 & 0,22 & 2 \\
\hline & 2,71 & 3,80 & 0,42 & 0,24 & 2 \\
\hline \multirow{5}{*}{5} & 2,28 & 3,43 & 0,81 & 0,15 & 3 \\
\hline & 2,29 & 3,45 & 0,81 & 0,15 & 3 \\
\hline & 2,25 & 3,45 & 0,81 & 0,15 & 3 \\
\hline & 2,29 & 3,45 & 0,76 & 0,13 & 3 \\
\hline & 2,30 & 3,46 & 0,77 & 0,13 & 3 \\
\hline
\end{tabular}

Hasil prediksi menggunakan model JST terlatih memiliki rentang nilai dari 0,13 \% hingga 0,29 \% untuk konsentrasi inokulum, Sedangkan untuk prediksi umur fermentasi, $76 \%$ hasil prediksi menunjukkan bahwa umur sampel tempe adalah 2 hari. Ini menunjukkan sampel tempe yang didapatkan dari pasaran masih berada pada rentang umur yang layak konsumsi dan dibuat dengan konsentrasi inokulum yang sesuai.

\subsection{Desain Aplikasi Perangkat Lunak}

Desain aplikasi perangkat lunak dimaksudkan agar mempermudah pengguna untuk mengetahui konsentrasi inokulum dan umur fermentasi dari sampel tempe. Perangkat lunak didesain dengan mengimplementasikan JST yang sudah terlatih dan sudah dilakukan pengujian sehingga memiliki nilai kesalahan 
yang kecil. Tampilan halaman masukan pada perangkat lunak dapat dilihat pada Gambar 13.

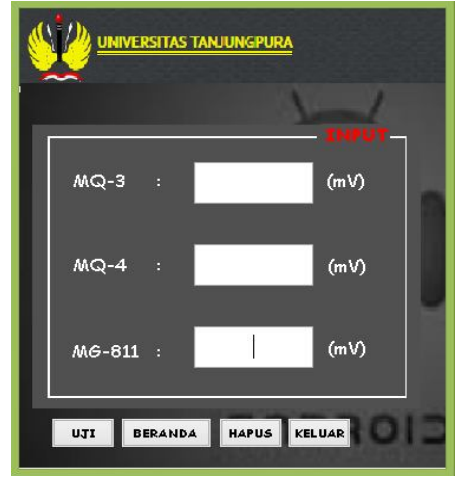

Gambar 13. Tampilan halaman masukan pada perangkat lunak

Halaman masukan berfungsi sebagai kolom masukan berupa nilai tegangan masing-masing sensor gas. Selanjutnya, hasil prediksi akan ditampilkan pada halaman prediksi. Tampilan halaman hasil prediksi dapat dilihat pada Gambar 14.

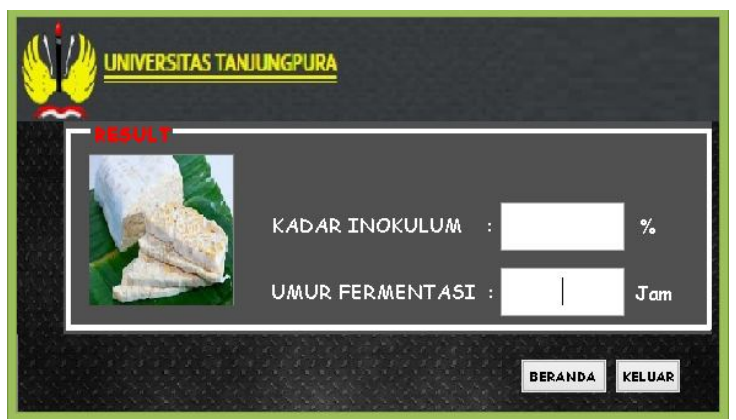

Gambar 14. Tampilan halaman hasil prediksi pada perangkat lunak

Hasil yang ditampilkan pada halaman ini merupakan keluaran jaringan terlatih yaitu nilai konsentrasi inokulum dalam satuan persentase (\%) dan umur fermentasi dalam satuan hari.

\section{Kesimpulan}

Berdasarkan penelitian yang telah dilakukan dapat disimpulkan bahwa larik sensor gas dapat dirancang menggunakan 3 buah komponen sensor gas dan dapat diintegrasikan dengan JST sebagai sistem pengolahan data unntuk memprediksi konsentrasi inokulum dan umur fermentasi pada tempe. Agar hasil prediksi lebih akurat, maka perlu dilakukan proses pelatihan pada JST. Pada penelitian ini pelatihan JST menghasilkan nilai korelasi yang sama untuk prediksi konsentrasi inokulum dan umur fermentasi yaitu 0,99, serta MSE 1,78.10-4 dan 8,83.10-4. Pengujian JST menghasilkan korelasi masing-masing 0,98 dan 0,99 dengan MSE $8,92 \cdot 10^{-5}$ dan $2,31 \cdot 10^{-3}$.

\section{Daftar Pustaka}

Bishop, Christopher M., 1995, Neural Networks for Pattern Recognition, University Science Books, Clarendon Press, Oxford.

Buyan, Stephanus, 2011, Prediksi Debit Aliran Sungai di Kecamaatan Air Besar (Serimbu) Menggunakan Jaringan Syaraf Tiruan Metode Propagasi Balik, Skripsi, Jurusan Fisika Universitas Tanjungpura.

Dewi, 2010, Karakteristik Sensoris, Nilai Gizi dan Aktivitas Antioksidan Tempe Kacang Gude (Cajanus Cajan (L,) Millsp,) dan Tempe Kacang Tunggak (Vigna Unguiculata (L,) Walp,) dengan Berbagai Variasi Waktu Fermentasi, Skripsi, Program Studi Teknologi Hasil Pertanian Universitas Sebelas Maret.

Dhaneswara, G., dan Moertini, V. W., 2004, Jaringan Syaraf Tiruan Propagasi Balik untuk Klasifikasi Data, Jurnal Integral Vol. 9, FMIPA Universitas Katolik Parahyangan.

2004 Kumalasari, R., 2012, Pengaruh Konsentrasi Inokulum Terhadap Kualitas Tempe Kedelai (Glycine max (L,) Merr) Var, Grobogan, Skripsi, Jurusan Kimia Universitas Kristen Satya Lencana, Salatiga.

Kusumadewi, Sri., 2004, Membangun Jaringan Syaraf Tiruan Menggunakan MATLAB \& EXCEL LINK, Graha Ilmu, Yogyakarta.

Ilmu Nugroho, J., 2008, Aplikasi Jaringan Syaraf Tiruan untuk Identifikasi Aroma Teh Menggunakan Electronic Nose, Seminar Nasional Teknik Pertanian UGM.

Oktorizal, A., 2010, Studi Sensor Gas Berbasis Surface Acoustic Wave untuk Penerapan pada Sistem Identifikasi Gas, Skripsi, Departemen Teknik Elektro Universitas Indonesia.

Rusnur, R, 2012, Rancang Bangun Alat Pendeteksi Gas LPG dengan Sensor TGS, Skripsi, Jurusan Teknik Elektro Universitas Gunadarma.

Siang, 2004, Jaringan Syaraf Tiruan dan Pemogramannya Menggunakan Matlab, ANDI, Yogyakarta.

Suprihatin, 2010, Teknologi Fermentasi, ISBN: 978-602-8915-50-2, UNESA University Press, Surabaya. 